\title{
Mixed Adenoneuroendocrine Gastric Carcinoma: A Case Report and Review of the Literature
}

\author{
Giovanni Battista Levi Sandri, Fabio Carboni, Mario Valle, Paolo Visca ${ }^{1}$, and Alfredo Garofalo \\ Department of Digestive Surgery, ${ }^{1}$ Department of Pathology, Regina Elena National Cancer Institute, Rome, Italy
}

We present a rare case of a gastric mixed adenoneuroendocrine tumor and review the related English literature. A 77-year-old Caucasian woman was admitted to our department with nausea, anorexia, weight loss, and anemia. Esophagogastroduodenoscopy showed a large $(>7 \mathrm{~cm})$ ulcerative mass in the greater curvature of the stomach. Biopsy showed the presence of an adenocarcinoma with moderate differentiation. The patient underwent D2 subtotal gastrectomy. Histopathological analysis revealed a diagnosis of mixed gastric adenoneuroendocrine carcinoma. The post-operative course was uneventful, and at the 6-month follow-up, the patient was alive without evidence of recurrence. Our review of the English literature suggested that such cases are most often reported from eastern countries. Multimodal treatment should be the aim for these patients because of the neuroendocrine component of the tumor.

Key Words: Stomach neoplasms; Mixed tumor; Collision tumor; Adenoneuroendocrine; Surgery

\section{Introduction}

Collision tumors with adenocarcinoma and neuroendocrine elements are commonly diagnosed in the gastrointestinal tract. However, the occurrence of neuroendocrine carcinoma (NEC) in the gastrointestinal tract is rare, ranging from $1 \%$ in the esophagus, $0.2 \%$ in the colon, and $0.1 \%$ to $0.4 \%$ in the stomach. ${ }^{1}$ Herein, we present a case of a mixed adenoneuroendocrine gastric tumor and review the English literature pertaining to such tumors.

\section{Case Report}

A 77-year-old Caucasian woman was admitted to our department with nausea, anorexia, weight loss, and anemia. The medical

Correspondence to: Giovanni Battista Levi Sandri

Department of Digestive Surgery, Regina Elena National Cancer Institute, Via Elio Chianesi 53, 00144, Rome, Italy

Tel: +39-6-52666789, Fax: +39-6-52662338

E-mail: gblevisandri@gmail.com

Received March 6, 2014

Revised March 20, 2014

Accepted March 21, 2014 history of the patient did not include any significant prior illness. The findings of physical examination were unremarkable. The patient's hemoglobin level $(10.3 \mathrm{~g} / \mathrm{dl})$ and tumor marker levels (carcinoembryonic antigen, carbohydrate antigen 19.9, and carbohydrate antigen 72-4) were within the normal range. Esophagogastroduodenoscopy revealed a large $(>7 \mathrm{~cm})$ ulcerative mass (Borrmann type 3) in the greater curvature of the stomach. Biopsy showed the presence of an adenocarcinoma with moderate differentiation. Computed tomography did not show distant metastasis. The patient underwent D2 subtotal gastrectomy, with no surgical complications. Histopathological analysis showed, in agreement with the diagnosis of a mixed gastric adenoneuroendocrine carcinoma (Fig. 1), that $30 \%$ of the tumor area was intensely positive for chromogranin (Fig. 2) and synaptophysin (Fig. 3), with part of it being tubular adenocarcinoma (G2) and of the rest being neuroendocrine large cell carcinoma (G3). The tumor penetrated the serosa, but none of the 29 regional lymph nodes showed metastasis and no distant metastasis was detected (pT4a, pNO, pMO, stage IIb according to the 7th edition of the American Joint Committee on Cancer TNM classification). The lymphatic and vascular lumina were not invaded, but perineural invasion was present. The post-operative 


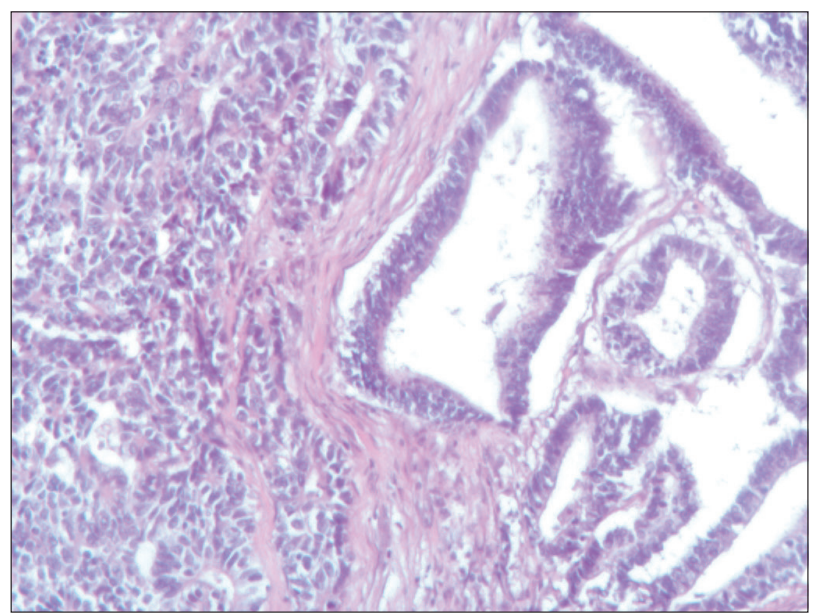

Fig. 1. The tumor lesion is composed of two separated and different features $(\mathrm{H} \& \mathrm{E}, \times 10)$.

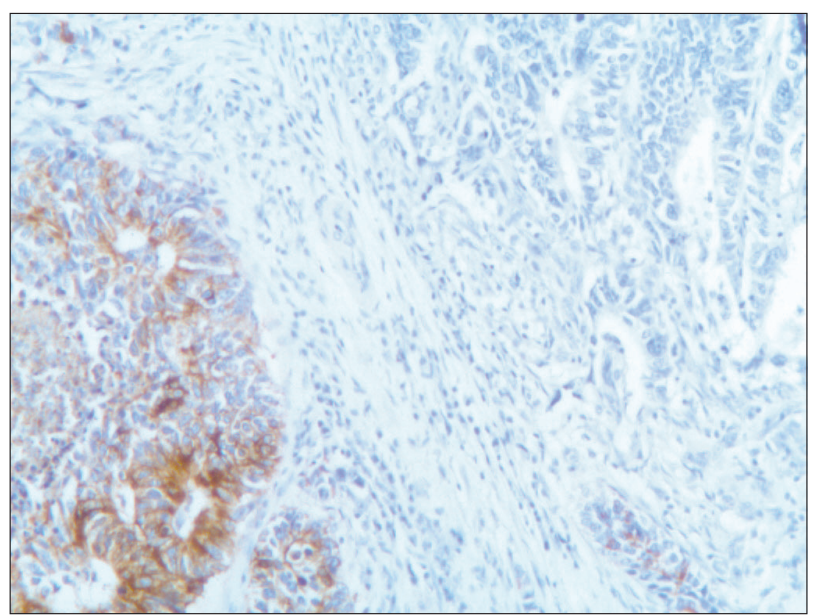

Fig. 2. Immunoreactivity of the mucosal and submucosal tumor cells for chromogranin (chromogranin, $\times 10$ ).

course was uneventful. The patient underwent adjuvant chemotherapy, consisting of a combination of cisplatin, doxorubicin, and vincristine, and at the 6-month follow-up, the patient was alive without evidence of recurrence.

\section{Discussion}

Collision tumors rarely occur in the gastrointestinal tract. Sporadic cases have been described, with less than 20 cases of such tumors in the stomach being reported, most often from eastern countries. The histological origin of composite tumors is unclear. Neuroendocrine tumors arise from embryonal neural crest cells, which are abundant in the epithelia of the gastrointestinal tract. In fact, some authors have postulated the proliferation of pluripotent

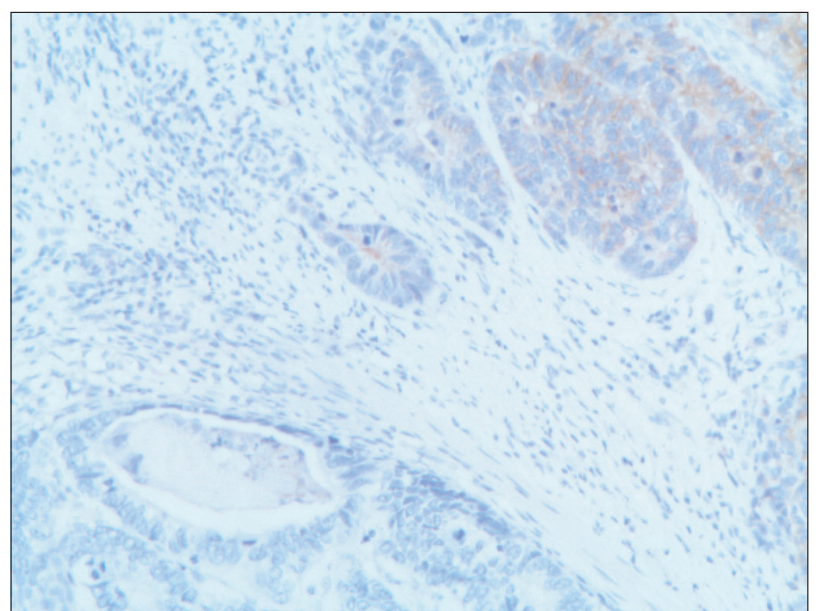

Fig. 3. Tumor cells of the neuroendocrine carcinoma stained positive for synaptophysin (synaptophysin, $\times 10$ ).

precursor cells. ${ }^{2}$ Lewin and Appleman ${ }^{3}$ classified gastric cancer into five groups: carcinoma with interspersed neuroendocrine cells, composite glandular-endocrine carcinomas, collision tumors (present case), amphicrine tumors, and a combination of all the above. In 2005, Fujiyoshi et al. ${ }^{4}$ revised the classification of mixed endocrine and non-endocrine epithelial tumors. This new classification included six groups: neuroendocrine cells interspersed within carcinomas; carcinoids with interspersed non-endocrine cells; composite glandular-neuroendocrine cell carcinomas containing both areas of a carcinoid component and conventional carcinoma; collision tumors in which neuroendocrine tumors and conventional carcinoma are closely juxtaposed, but not admixed (present case); amphicrine tumors predominantly composed of cells exhibiting concurrent neuroendocrine and non-endocrine differentiation; and combinations of the previous types. ${ }^{4}$ In 2010, the World Health Organization classification of gastrointestinal tumors classified mixed tumors into three groups according to prognosis: high-grade malignant (mixed adenoma/adenocarcinoma-neuroendocrine carcinoma; present case), intermediate-grade malignant (mixed adenocarcinoma G1/G2 neuroendocrine tumor), low-grade malignant (adenoma-neuroendocrine tumor). ${ }^{5}$

We reviewed the English literature pertaining to gastric mixed tumors (Table 1$)^{6-20}$ and found that most such cases have been reported from eastern countries, probably because of the overall high incidence of gastric tumors in these countries. The 5-year survival rate is lower for these patients than for those with gastric adenocarcinoma. The neuroendocrine component may have a considerable impact on the prognosis. ${ }^{21}$ Because of the mixed component of the tumor, treatment should focus on parts of the tumor with the more 
Mixed Adenoneuroendocrine Gastric Carcinoma

Table 1. Review of the English literature pertaining to gastric collision tumors

\begin{tabular}{|c|c|c|c|c|c|}
\hline Author & Patient's age (yr) & Gender & Location & Borrmann type & Follow-up period \\
\hline Yamashina and Flinner ${ }^{6}$ & 50 & Male & Middle body & 1 & Unknown \\
\hline Chodankar et al. ${ }^{7}$ & 69 & Female & Body & 1 & Death within 6 months \\
\hline Morishita et al. ${ }^{8}$ & 49 & Male & Upper body & 3 & Unknown \\
\hline Corsi and Bosman ${ }^{9}$ & 72 & Male & Unknown & Unknown & Unknown \\
\hline Camuñas Mohinelo et al..$^{10}$ & 66 & Male & Cardia & Unknown & Unknown \\
\hline Morishita et al. ${ }^{11}$ & 84 & Female & Cardia & 3 & 2 years 9 months \\
\hline Jayaraman et al. ${ }^{12}$ & 48 & Female & Pylorus & Unknown & Unknown \\
\hline Jeong et al. ${ }^{13}$ & 57 & Unknown & Antrum & 3 & Unknown \\
\hline Mróz et al. ${ }^{14}$ & 56 & Male & Body & 2 & 2 months \\
\hline Jang et al. ${ }^{15}$ & 50 & Male & Lower body & 3 & Unknown \\
\hline Boşoteanu et al. ${ }^{16}$ & 52 & Male & Middle body & Unknown & Unknown \\
\hline Lee et al. ${ }^{17}$ & 62 & Male & Lower body & 1 & Unknown \\
\hline Kim et al. ${ }^{18}$ & 62 & Female & Antrum & 3 & Unknown \\
\hline Miguchi et al. ${ }^{19}$ & 72 & Male & Middle body & 1 & 6 months \\
\hline Pericleous et al. ${ }^{20}$ & 81 & Male & Antrum & 3 & Unknown \\
\hline
\end{tabular}

aggressive cells. In cases of well-differentiated neuroendocrine components with benign or low-grade malignant behavior, chemotherapy should focus on the exocrine component. In contrast, in cases of small cell NEC or large cell NEC, the endocrine component should be the main target of the therapy. ${ }^{17}$

After radical surgical resection, a chemotherapy regimen consisting of cisplatin, doxorubicin, and vincristine is highly recommended.

Mixed adenoneuroendocrine tumors are rare, but they are now well classified. Multimodal treatment should be the aim for these patients because of the neuroendocrine component of the tumor.

\section{References}

1. Jass JR, Sobin LH, Watanabe H. The World Health Organization's histologic classification of gastrointestinal tumors. A commentary on the second edition. Cancer 1990;66:21622167.

2. Lee EJ, Park SM, Maeng L, Lee A, Kim KM. Composite glandular-endocrine cell carcinomas of the stomach: clinicopathologic and methylation study. APMIS 2005;113:569-576.

3. Lewin KJ, Appleman HD. Endocrine cell proliferation of the stomach. In: Lewin KJ, Appelman DH, eds. Atlas of Tumor Pathology: Tumors of the Esophagus and Stomach. Washington, D.C.: Armed Forces Institute of Pathology, 1996:3-16.

4. Fujiyoshi Y, Kuhara H, Eimoto T. Composite glandular- endocrine cell carcinoma of the stomach. Report of two cases with goblet cell carcinoid component. Pathol Res Pract 2005;200:823-829.

5. Bosman TF, Carneiro F, Hruban RH, Theise ND, eds. WHO Classification of Tumours of the Digestive System. 4th ed. Lyon: International Agency for Research on cancer (IARC), 2010:13.

6. Yamashina M, Flinner RA. Concurrent occurrence of adenocarcinoma and carcinoid tumor in the stomach: a composite tumor or collision tumors? Am J Clin Pathol 1985;83:233-236.

7. Chodankar CM, Pandit SP, Motiwale SS, Deodhar KP. Collision tumour of stomach. Indian J Gastroenterol 1989;8:297298.

8. Morishita Y, Tanaka T, Kato K, Kawamori T, Amano K, Funato $\mathrm{T}$, et al. Gastric collision tumor (carcinoid and adenocarcinoma) with gastritis cystica profunda. Arch Pathol Lab Med 1991;115:1006-1010.

9. Corsi A, Bosman C. Adenocarcinoma and atypical carcinoid: morphological study of a gastric collision-type tumour in the carcinoma-carcinoid spectrum. Ital J Gastroenterol 1995;27:303-308.

10. Camuñas Mohinelo FA, Melgar Requena P, Martínez Zaragoza J, Estrada Caballero JL, Jiménez Torres MJ, Arroyo Guijarro A. Gastric collision tumor with osseous metaplasia. Rev Esp Enferm Dig 1997;89:317-319.

11. Morishita Y, Sugitani M, Sheikh A, Nemoto N, Fujii M, 
Levi Sandri GB, et al.

Takayama T. Collision tumor of the stomach: a rare case of an adenocarcinoma and carcinoid tumor. Arch Pathol Lab Med 2005;129:407-409.

12. Jayaraman A, Ramesh S, Jeyasingh R, Bagyalakshmi KR. Gastric collision tumour--a case report. Indian J Pathol Microbiol 2005;48:264-265.

13. Jeong SW, Kim YS, Cho JY, Jung IS, Hong SJ, Ryu CB, et al. A case study of a gastric collision tumor with an adenocarcinoma and a carcinoid tumor. Korean J Gastrointest Endosc 2008;36:159-164.

14. Mróz A, Kiedrowski M, Malinowska M, Sopyło R. Collision tumour of the stomach--adenocarcinoma and neuroendocrine carcinoma: case report and review of the literature. Pol J Pathol 2009;60:94-97.

15. Jang KY, Moon WS, Lee H, Kim CY, Park HS. Gastric collision tumor of large cell neuroendocrine carcinoma and adenocarcinoma--a case report. Pathol Res Pract 2010;206:387-390.

16. Boşoteanu M, Boşoteanu C, Deacu M, Aşchie M. Morphological and immunohistochemical characteristics of a gastric amphicrine tumor: differential diagnosis considerations. Rom
J Morphol Embryol 2011;52(1 Suppl):485-488.

17. Lee HH, Jung CK, Jung ES, Song KY, Jeon HM, Park CH. Mixed exocrine and endocrine carcinoma in the stomach: a case report. J Gastric Cancer 2011;11:122-125.

18. Kim JJ, Kim JY, Hur H, Cho YK, Han SU. Clinicopathologic significance of gastric adenocarcinoma with neuroendocrine features. J Gastric Cancer 2011;11:195-199.

19. Miguchi M, Iseki M, Shimatani K. Advanced gastric neuroendocrine carcinoma with an adenocarcinoma component. Case Rep Gastroenterol 2012;6:52-57.

20. Pericleous M, Toumpanakis C, Lumgair H, Caplin ME, Morgan-Rowe L, Clark I, et al. Gastric mixed adenoneuroendocrine carcinoma with a trilineage cell differentiation: case report and review of the literature. Case Rep Oncol 2012;5:313319.

21. Elias D, Cavalcanti de Albuquerque A, Eggenspieler P, Plaud B, Ducreux M, Spielmann M, et al. Resection of liver metastases from a noncolorectal primary: indications and results based on 147 monocentric patients. J Am Coll Surg 1998;187:487-493. 